\title{
Investigating the Effects of Group Investigation (GI) and Cooperative Integrated Reading and Comprehension (CIRC) as the Cooperative Learning Techniques on Learner's Reading Comprehension
}

\author{
Mohammad Amin Karafkan \\ English Department, Literature \& Foreign Languages Faculty, Tabriz University, Tabriz, Iran \\ E-mail: amin.karafkan2020@yahoo.com \\ Zahra Aghazadeh (Corresponding author) \\ Department of English, Faculty of Humanities, Urmia University, Urmia, Iran \\ E-mail: z.aghazadeh@urmia.ac.ir
}

\author{
Received: 01-03- 2015 \\ Accepted: 06-06- 2015 \\ Advance Access Published: August 2015 \\ Published: 01-11- 2015 \\ doi:10.7575/aiac.ijalel.v.4n.6p.8 \\ URL: http://dx.doi.org/10.7575/aiac.ijalel.v.4n.6p.8
}

\begin{abstract}
Cooperative learning consists of some techniques for helping students work together more effectively. This study investigated the effects of Group Investigation (GI) and Cooperative Integrated Reading and Composition (CIRC) as cooperative learning techniques on Iranian EFL learners' reading comprehension at an intermediate level. The participants of the study were 207 male students who studied at an intermediate level at ILI. The participants were randomly assigned into three equal groups: one control group and two experimental groups. The control group was instructed via conventional technique following an individualistic instructional approach. One experimental group received GI technique. The other experimental group received CIRC technique. The findings showed that there was a meaningful difference between the mean of the reading comprehension score of GI experimental group and CRIC experimental group. CRIC technique is more effective than GI technique in enhancing the reading comprehension test scores of students.
\end{abstract}

Keywords: GI, CIRC, Cooperative Learning Techniques, Reading Comprehension

\section{Introduction}

Human is one of the animals who prefer social life to individual life. Cooperation is working together to accomplish shared goals. The value of cooperative learning has been identified throughout human history. Organizing individuals to work in support of one another and to put the interests of the group ahead of one's own are abilities that have described some of the most fortunate people of our time. Cooperative learning is now acknowledged as one of the most promising practices in the field of education. Within cooperative activities individuals look for the results that are helpful to themselves and useful to all other group members. Cooperative learning is the instructional application of small groups so that students work together to increase their own and each other's learning. The idea is manageable. Class members are categorized into small groups after receiving instruction from the teacher. They then work through the assignment until all group members successfully understand and complete it.

The idea of cooperative learning is not new. Joseph Lancaster and Andrew Bell brought the idea of cooperative groups to America as early as 1700s. They inaugurated the Lancastrian School in 1806 with a strong emphasis on cooperative learning due to the variety of the cultural backgrounds from which students came. Later, during the early 1900s, scientists became interested in and started investigating the effects of cooperative learning on human behavior (Klimoviene \& Statkeviciene, 2006). Among the most influential characters was John Dewey, who became well-known in the field with his book entitled Democracy and Education in 1906. Dewey was interested in cooperative learning since the process of learning was more important than its content for him. To him, the primary aim of education was to develop socially responsible citizens who could cooperate to solve problems (Broody, Baloche, Schmuck, Sherman \& Sharan, 2004). He posited that education was a primary aspect of living and that it was the school's responsibility to realize children's interests, to shape and boost them, and to help them react appropriately in novel situations. He mentioned that a school should be a place to build on the students' inner interests in their environment by enhancing interpersonal communication and encouraging group involvement. The process of learning in school is a social, emotional, and intellectual process (Passi \& Vahtivuori, 2001). To approach this major goal, Dewey argued that students should be taught directly to empathize with others, to respect the rights of others and to work together rationally (Brody et al., (2004). 
Humans are social creatures by nature due to which they eagerly seek occasions to negotiate with each other and almost "90 percent of all human interaction is cooperative" (Chester, 2009, p.4). That's why in all types of classes - even those conducted in an individualistic fashion- we notice students striving to consult with each other. This inner willingness of students when paid attention to and leaded to the right channels will bring about positive changes.

One of the main problems confronting EFL learner is how to improve his/her reading comprehension. Reading is necessary when learners want to develop their study. They need a high-quality reading skill for acquiring knowledge and new information. Having a high-quality reading skill, is the concern of both EFL learners and instructors.

Cooperative Learning (CL) and Conventional Instruction (CI) are two approaches that are generally applied in the classroom, and the results indicated that some are successful in presenting reading comprehension with a particular group of students. There is more than one flavor of cooperative learning (Kluge, et al, 1999) operationalized into a number of techniques and structures (Shaaban \& Ghaith, 2005) such as: Teams-Games Tournaments (TGT), Group Investigation (GI), Constructive Controversy (CC), Jigsaw, Student Teams Achievement Divisions (STAD), and Curriculum Packages: Cooperative Integrated Reading and Composition (CIRC). To our knowledge, there are not any investigation about the effect of Group Investigation (GI) technique on learner's reading comprehension of both advanced and intermediate groups. The aim of this study is investigate and to compare the effect of Group Investigation (GI) and Cooperative Integrated Reading and Composition ( CIRC) as cooperative learning techniques on Iranian EFL learners' reading comprehension at intermediate level. The results can shed light on the effectiveness of techniques of cooperative learning.

\subsection{Research Questions}

Q1. Is there any significant relationship between CIRC and GI in the reading comprehension test scores before the treatment (that is all of the three groups are homogeneous)?

Q2. Is there any significant relationship between control and GI groups in the reading comprehension test scores after the treatment?

Q3. Is there any significant relationship between control and CRIC groups in the reading comprehension test scores after the treatment?

Q4. Is there any significant difference in the mean score of reading comprehension between the experimental group of GI and experimental of CRIC after the treatment?

\subsection{Research Hypothesis}

H1. There is not any significant relationship between CIRC and GI in the reading comprehension test scores before the treatment (that is all of the three groups are homogeneous)

H2. There is not any significant relationship between control and GI groups in the reading comprehension test scores after the treatment.

H3. There is not any significant relationship between control and CRIC groups in the reading comprehension test scores after the treatment.

H4. There is not any significant difference in the mean score of reading comprehension between the experimental group of GI and experimental of CRIC after the treatment.

\section{Literature Review}

One of the main problems confronting EFL learners is how to enhance their reading comprehension. Reading is necessary when learners want to expand their investigations. They need a high-quality reading skill for acquiring knowledge and new information. Having a high-quality reading skill is the concern of both EFL learners and instructors. Many researchers have been interested in investigating strategies that help students have better understanding when they read. Cooperative Learning (CL) and Conventional Instruction (CI) are the instances of approaches that have been extensively used in classroom and the results have indicated that some are doing well in presenting reading comprehension with a particular group of students. While some are not. Still, there is a need to take into consideration the way that knowledge is presented to the students on the printed page.

\subsection{The Underlying Theories of Cooperative Learning}

Cooperative learning as a teaching technique has proved successful in most of the countries because of a rich and clear theoretical foundation. Many theories of SLA (Second Language Acquisition) and general education can be seen as supportive of the use of cooperative learning in L2 instruction including Input Hypothesis, Interaction Hypothesis, Output Hypothesis, Socio-cultural Theory, Individual Differences, and Learner Autonomy (Jacobs, 2004).

The Input Hypothesis: In cooperative learning "input from group mates may be more likely to be comprehensible as group mates' language levels may be roughly equal "(ibid, p.2). The input that the learners receive from each other is comprehensible, communicative, and usually it contains examples of $i+1$. Krashen's Input Hypothesis is sure affected by Vygotsky's Zone of Proximal Development.

The Interaction Hypothesis: According to Long (1985) we can say interactional adjustments improve comprehension, and comprehension allows acquisition" (Spada \& Lightbown, 2002, p.122). The collaborative situation in groups and the trust which is present among group members provide the opportunities to renovate comprehension breakdowns (Jacobs, 2004). Groups provide a means for the students to participate in an interaction in the target language. Groups 
stimulate natural language activities in the classroom. Furthermore, although groups are associated with fluency practice, students can also do accuracy work in groups.

The Output Hypothesis: Many researchers in second language acquisition argue that successful language learning doesn't only rely on comprehensible input, but also comprehensible output (Liang, 2002). Moreover, according to the Output Hypothesis, the output should also be given due attention. In addition to the comprehensibility of input which should be provided for the learners, their output (speaking and writing) should be considered as well. This aim wouldn't have been achieved in traditional classrooms because of the teacher's dominance that would confine students' efficiency, but it can easily be achieved in cooperative learning since learners working in groups needs to increase their productivity.

Socio- Cultural Theory: Socio- Cultural Theory is originated from Vygotsky. Vygotsky puts learning as a social process in which learners internalize what has been shared between them by mediational means. The socio- cultural theory applies to almost all different social situations and its main outstanding concept is "higher forms of mental activity are mediated" (Ellis, 2003, p. 176). The theory attempts to explain how mediated minds are developed out of a social activity. Lantolf $(2000$, as cited in Ellis ,2003) argues that the mediation in second language learning involves: a: Mediation by others in social interaction; b: Mediation by self through private speech; c: Mediation by artifacts. This viewpoint is emphasized on the manner that L2 learners mediate learning following context (including peers) and experience with others (Jacobs, 2004, Chastain, 1988).

Individual Differences: Learners differ in terms of intelligence, learning styles and learning strategies and these differences must be taken into account. One of the crucial differences between individuals is that some of the learners desire to learn in social situations. All learners need to know how to promote in such situations and cooperative learning provides opportunities to promote and practice the strategies they need to work with others.

Learner Autonomy: Recently, acknowledgment of the centrality of the learner has grown stronger. Modern education tries to help learners become independent beings and lifelong learners. Group activities provide opportunities for students to become less dependent on their teachers (Jacobs, 2004) by giving them chances to plan, control and evaluate their and their group mates' learning.

\subsection{Elements of Cooperative Learning}

Every time two individuals interact, the potential for cooperation exists. However, it is only under certain conditions that we can say cooperation does exist. As a highly structured method, cooperative learning encompasses five important elements. These inevitable elements are:

Positive Interdependence: Positive interdependence is the belief by each that there is a value in cooperating with other students and that both individual learning and performance will be improved as a result of collaboration.

Individual Accountability / Personal Responsibility: "Individual accountability exists when the performance of each member is assessed, and the results are given back to the individual and the group to compare against a standard of performance" (Johnson \& Johnson, 2009a, p. 368).

(Face-to-Face) Promotive Interaction: In addition to individual accountability positive interdependence also, results in the promotive interaction. Promotive interaction refers to the act of students encouraging and helping each other to achieve the group's goal.

Appropriate Use of Social Skills: As we know, socially unskilled group members cannot cooperate effectively. These skills vary according to the age of the students and the cultural context, but can include such skills as: asking for help, giving reasons, speaking at an appropriate volume level, disagreeing politely, paraphrasing, asking for repetition, listening attentively, and many others. In order for the group members to achieve their desired goals they must: 1) get familiar with and trust each other, 2) communicate accurately and unambiguously, 3) accept the differences and support each other, 4) resolve conflict constructively (Johnson \& Johnson, 2009b).

Group Processing: Group work is highly influenced by whether or not group members reflect on their work. Group processing occurs when group members think about that which member actions were cooperative and uncooperative and decide which actions should be continued or changed (Johnson \& Johnson, 2009a). Providing time for individual and group reflection will increase the quality of cooperative learning teams by strengthening intrapersonal and interpersonal competencies (Jones \& Jones, 2008).

\section{Method}

\subsection{Participants and the Context of the Study}

The statistical population of the study was 450 students. According to the Coceran formula the sample size was 207 students. All of the students were male, and they were studying at the intermediate level in ILI. The majority of students are 17 years old, and they constitute 45 percents of participants. 18 year- old students constitute 30 percents and 16 year -old students constitute 24 percents of participants. All participants were native Persian-speaking learners of English as a foreign language who had never lived or traveled to an English-speaking country. However, almost all of the students took English classes in other language centers before the study. The student in the experiment and control groups at intermediate level were instructed by the same teacher who had 10 years of experience of full-time service and who had also received training in using GI and CIRC techniques to teach the topics included in the instructional units under investigation. 
According to Mackey and Gass (2005, p.137), quantitative research is divided into two types: associational and experimental. This study complies with an experimental design since, in experimental studies "researchers deliberately manipulate one or more variables (independent variables) to determine the effect on another variable (dependent variable)". Another definition for experimental design is offered by Cook and Campbell (1979 as cited in Griffee, 2012, p.71): "All experiments involve at least a treatment, an outcome measure, units of assignment, and some comparison from which change can be inferred and hopefully attributed to the treatment". In these types of studies the researcher investigates whether there is a causal relationship or not. As already mentioned, the present study used a control group and two experimental groups. Implicit in the use of control groups is that the control groups represent the same participants as the experimental groups. In order to satisfy this requisite, a proficiency test was administered so that it can be claimed that both the control group and the experimental group are at the same proficiency (intermediate) level.

\subsection{Materials}

To start with, a reading comprehension test that was adapted from a TOEFL PBT was administered to the students. Those who had the high score in that test were divided into three groups. At the end, all participants, two experimental groups and one control group, took the reading comprehension test which was adapted from a TOEFL in order to determine whether there was any significant difference between the two experimental groups' mean score after the treatment. The instruments of the study were passages for both intermediate levels. Each passage has several units. Each unit has several heading and subheading and their readings.

\subsection{Data Collection Procedures}

The informed consent forms were distributed to students. A proficiency test was administered to ensure inter-group homogeneity. That is the TOEFL test was used as a pre-test for intermediate level students. Those who passed the TOEFL test from 207 students were randomly divided into three groups: two experimental group and one control group. The control group was instructed via conventional technique following an individualistic instructional approach. In the control group, the teacher began each new reading passage by reading it aloud and then translating each sentence into the students' native language, i.e., Persian. After transmitting the required knowledge, the teacher asked some of the students to answer the exercises individually. The interaction in the classrooms that had conventional instruction was typically teacher-initiated, and the teacher started the conversation and the learner-learner interaction was limited.

The one experimental group received GI technique as investigation, interaction, interpretation, and intrinsic motivation. Students were assigned to several groups based on the common interest in a specific subtopic of units and teacher's decision about the size of the group. At first, the students at each group read the reading comprehension individually within a limited time (10 to 15 minutes). Then the teacher asked each group to investigate and exchange ideas about the topic of reading through interaction. Then they exchanged their ideas about the meaning as well as the structure, or they asked each other some questions about some parts of reading that they were not able to follow successfully. Each group could cooperate with the teacher, and they could integrate its finding with the teacher.

The other experimental group received CIRC technique. The focus of this technique was on the reading and writing. The teacher selected the group the students and the students were paired with their groups. Then the students worked on the reading material in their pairs, and they tried to teach and learn from each other the reading material. Then the student was paired with another member of the group and again, they helped each other to master the reading strategy such as summarizing, guessing and asking questions about the content of the reading. This process continued with other students in different groups and student of one group went to the other group to gain knowledge about the reading and to cooperate with each other. Then the students returned to their original group, and the teacher assessed their group works. At the end, all the subjects, the two experimental groups as well as one control group at the level of intermediate took the TOEFL reading passages as a post-test in order to determine whether there were any significant differences between two experimental groups' mean score or not.

\subsection{Data Description}

Table3.1 The descriptive statistics of the test score of the control group

\begin{tabular}{cccc}
\hline & \multicolumn{3}{c}{ Control group } \\
\hline Number & SD & Mean & \\
\hline 33 & $2 / 74$ & $23 / 57$ & Before the course \\
\hline 33 & $2 / 39$ & $24 / 67$ & After the course
\end{tabular}

According to the above table, the mean score of control group before and after the course has not changed significantly. Their mean of the score was 23.57 before the course and 24.67 after the course.

Table 3.2 The descriptive statistics of the test score of the experimental group of GI

\begin{tabular}{cccc}
\hline \multicolumn{4}{c}{ The experimental group of GI } \\
\hline Number & SD & Mean & \\
\hline 33 & $2 / 23$ & $24 / 33$ & Before the course \\
\hline 33 & $3 / 78$ & $29 / 39$ & After the course \\
\hline
\end{tabular}


According to the above table, the mean of test score of the experimental group of GI is more than before that is the teaching of GI technique has influenced positively on the reading comprehension score.

Table 3.3 The descriptive statistics of the test score of the experimental group of CIRC

\begin{tabular}{cccc}
\hline \multicolumn{4}{c}{ CIRC Experimental group } \\
\hline Number & SD & Mean & \\
\hline 33 & $2 / 93$ & $25 / 81$ & Before the treatment \\
\hline 33 & $3 / 70$ & $32 / 69$ & After the treatment \\
\hline
\end{tabular}

According to the above table, the mean of test score of the experimental group of CIRC is more than before that is the teaching of CIRC technique has influenced positively on the reading comprehension score.

\section{Data analysis according to the research hypothesis}

The findings of the study were investigated according to the research hypotheses, and the aim of this analyze is to infer and conclude the features of the population which the sample has been derived. In order to examine the hypothesis of this study, The Independent sample t-test has been used.

Hypothesis 1. There is not any significant relationship between CIRC and GI in the reading comprehension test scores before the treatment (that is all of the three groups are homogeneous)

This test has been used in order to show that the three groups are similar for implementing the treatment, and there is not any significant difference between the mean of TOEFL score in three groups. So, the t-test has been used.

Table 4.1 Descriptive statistics of three groups before the treatment

\begin{tabular}{llll}
\hline SD & Mean & Numbers & Croups \\
\hline $2 / 74$ & $23 / 57$ & 33 & First \\
\hline $2 / 39$ & $24 / 67$ & 33 & Second \\
\hline $2 / 93$ & $25 / 81$ & 33 & Third \\
\hline
\end{tabular}

According to the above table, the mean score of the first group before the course is 23.57 . We recognize this group as the control group. The mean score of the second group before the treatment is 24.67 . We identify this group as the experimental group of GI group. The mean score of the third group before the treatment is 25.81 . We recognize this group as the experimental group of CIRC.

Table 4.2 Independent Sample t-test

\begin{tabular}{llll}
\hline Sig & Degree of freedom & Statistics $t$ & Variable \\
\hline $0 / 19$ & 64 & $-1 / 32$ & First and second group \\
\hline $0 / 08$ & 64 & $-1 / 25$ & First and third group \\
\hline $0 / 10$ & 64 & $-1 / 36$ & Second and third group \\
\hline
\end{tabular}

The significant value of the difference between first and second group at the error level of 0.05 is 0.19 which is more than 0.05. So it can be claimed that there is not any significant difference between the mean of the reading comprehension score of first and second group. The significant value of the first and the third group is 0.08 , and it is more than 0.05 . So it is claimed that there is not any significant difference between the mean of the reading comprehension score of first and third group. The same result has been obtained for the second and third group, and there is not any significant difference mean of the reading comprehension score of second and third group

Hypothesis 2: There is not any significant relationship between control and GI groups in the reading comprehension test scores after the treatment.

Table 4.3 Descriptive statistics of reading comprehension score of the TOEFL

\begin{tabular}{llll}
\hline SD & Mean & Number & Croups \\
\hline $2 / 39$ & $24 / 67$ & 33 & Control \\
\hline $3 / 78$ & $29 / 39$ & 33 & Experimental group of GI \\
\hline
\end{tabular}

The above table shows the reading comprehension mean score of the control group and experimental group of GI. While it is apparent from the table, the mean score for reading comprehension for the control group is 27.67 and for the GI group is 29.39. So the mean score of the experimental group of GI is more than that in the control group.

Table 4.4 Independent Sample t-test

\begin{tabular}{llll}
\hline Sig & Degree of freedom & Statistics t & Variable \\
\hline $0 / 001$ & 64 & $-6 / 67$ & $\begin{array}{l}\text { Reading } \\
\text { comprehension }\end{array}$ \\
\hline
\end{tabular}


The significant value of the difference between control group and experimental group of GI at the error level of 0.05 is 0.001 which is less than 0.05 . So it can be claimed that there is the significant difference between the mean of the reading comprehension score of control and experimental group of GI. That is the GI technique has the positive influence on the scores of reading comprehension test.

Hypothesis 3: There is not any significant relationship between control and CRIC groups in the reading comprehension test scores after the treatment.

In order to test this hypothesis, independent sample t-test is used.

Table 4.5 Descriptive statistics of students' reading comprehension score

\begin{tabular}{llll}
\hline SD & Mean & Number & Croups \\
\hline $2 / 39$ & $24 / 67$ & 33 & Control group \\
\hline $3 / 70$ & $32 / 69$ & 33 & Experimental group of CRIC \\
\hline
\end{tabular}

The above table shows the reading comprehension mean score of a control group and experimental group of CRIC. As it is apparent from the table, the mean score for reading comprehension for the control group is 27.67 and for the CRIC group is 32.69. So the mean score of experimental group of CRIC is more than that in control group

Table 4.6 Independent Sample t-test

\begin{tabular}{llll}
\hline Sig & Degree of freedom & Statistics t & Variable \\
\hline $0 / 001$ & 64 & $-10 / 39$ & $\begin{array}{l}\text { Reading } \\
\text { comprehension }\end{array}$ \\
\hline
\end{tabular}

The significant value of the difference between control group and experimental group of CRIC at the error level of 0.05 is 0.001 which is less than 0.05 . So it can be claimed that there is the significant difference between the mean of the reading comprehension score of control and experimental group of CRIC. That is the CRIC technique has the decisive influence on the scores of reading comprehension test.

Hypothesis 4. There is not any significant difference in the mean score of reading comprehension between the experimental group of GI and experimental of CRIC after the treatment.

In order to test this hypothesis, independent sample t-test is used

Table 4.7 Descriptive statistics of students' reading comprehension score

\begin{tabular}{llll}
\hline SD & Mean & Number & Croups \\
\hline $3 / 78$ & $29 / 39$ & 33 & Experimental group of GI \\
\hline $3 / 70$ & $32 / 69$ & 33 & Experimental group of CRIC \\
\hline
\end{tabular}

The above table shows the reading comprehension mean score of the experimental group of GI and experimental group of CRIC. As it is evident from the table, the mean score for reading comprehension for the GI experimental group is 29.39 and for the CRIC group is 32.69. So the mean score of experimental group of CRIC is more than that in GI experimental group.

Table 4.8 Independent Sample t-test

\begin{tabular}{llll}
\hline Sig & Degree of freedom & Statistics t & Variable \\
\hline $0 / 001$ & 64 & $-3 / 57$ & $\begin{array}{l}\text { Reading } \\
\text { comprehension }\end{array}$ \\
\hline
\end{tabular}

The significant value of the difference between GI experimental group and CRIC experimental group at the error level of 0.05 is 0.001 which is less than 0.05 . So it can be claimed that there is the significant difference between the mean of the reading comprehension score of GI experimental group and CRIC experimental group. So the hypothesis based on the difference between the mean score for reading comprehension between GI experimental group and CRIC experimental group is accepted. According to the above table which shows that the mean score of reading comprehension of CRIC experimental group is more than that in GI experimental group, it can be said that CRIC technique is more effective than GI technique in enhancing the reading comprehension test scores of students.

\section{Discussion and Conclusion}

The key purpose of this study was to investigate the effectiveness of Group investigation and Cooperative Integrated Reading and Composition as two techniques of Cooperative learning on reading comprehension of EFL intermediate learners. The results of this study suggest that cooperative learning is more effective than conventional instruction (CI) in improving EFL reading achievement of intermediate learners which confirms the findings by Ghaith (2003), Myers (2006), Tracy and Barbara (2003), and Wilson (1991) that stated related results with respect to the positive outcomes of 
CL in developing reading comprehension performance. Gaith (2003) examined the results of the Learning Together cooperative learning model in developing English as a Foreign Language (EFL) reading comprehension and educational self-esteem and in decreasing feelings of school alienation. His results revealed a statistically significant difference in favor of the experimental group on the variable of EFL reading achievement. Myers (2006) argued that cooperative strategy is one the six techniques six techniques and approaches for improving reading comprehension reading comprehension. Tracy and Barbara (2003) showed that there is a greater understanding and overall comprehension development when children work together sharing their perceptions of text in reading comprehension. Moreover, the findings of Wilson study (1991) showed that there was a notable difference in the reading comprehension of those students participated and those not involved in cooperative learning strategies.

However, what makes the present study significant is the superiority of CIRC as one technique in cooperative learning among intermediate learners. In the cooperative classroom certain relationships among all group-mates support learners to encourage each other and use more effort to obtain group success while in the non-cooperative classroom negative interdependence is dominant since the progress of high-achieving students may result in reducing the possibilities for their low-achieving counterparts. Students in cooperative groups receive encouragement and support from their more competent peers. They may understand that their contributions are valued for the success of the group. Their peers are available to help them when they need an answer to a question or solution to a problem. When someone creates an incorrect response, the more able students in the group can explain why that answer is not acceptable, and this explanation can increase interaction among group members, which can promote deeper learning of materials through explanation, elaboration, or mental processing which take place during this interaction. Nevertheless, where the course is obligatory, such as is the case with the students in the present study, external factors can be stronger and more persuasive elements than intrinsic motivation to keep learners more involved, hence the better performance of learners instructed through CIRC (Keshavarz et al. 2014).

Maden et al. (1986a, b) and Stevens et al. (1995) studies confirmed this result, that is the effectiveness of CIRC technique on reading comprehension. Zarei (2012) investigated the effects of the 'Student Teams-Achievement Divisions' (STAD) and 'Cooperative Integrated Reading and Composition' (CIRC) cooperative learning models in reading achievement and vocabulary learning of Iranian learners of English. He also found out the effectiveness of CIRC technique on reading comprehension.

Gupta and Ahuja also confirmed the effectiveness of CIRC technique. In their study, the mean gain Reading Comprehension achievement scores in English of experimental group and control group of seventh graders differ significantly in favor of the experimental group. This suggests that students who are taught English through cooperative learning strategy CIRC benefited more in their Reading Comprehension achievement than the students who received instructions through the conventional method of teaching.

In addition, according to Jalilifar (2010), the theoretical relevance of CL in increasing the students' reading ability is based on the assumption that students in CL may feel important because they perform roles that are necessary to the completion of group tasks. Moreover, they possess information that are essential for their teams. Therefore, interaction among team members can bring about an increased achievement through elaboration and organization of the material prepared by the teacher. This is in line with the finding of the cognitive elaboration perspective that cooperative learners must engage in some cognitive restructuring or elaborating to keep information in memory and incorporate it into the existing cognitive structures (Johnson et al., 1998, as cited in Jalilifar, 2010). However, interaction does not, per se, account for the conflicting results of CIRC and GI as two techniques in cooperative learning.

The results of the existing study indicated that GI technique is more effective than CI in reading comprehension of EFL intermediate learners which is in line with Jalilifar's study (2010) which specify that despite the basic differences between the CI and GI techniques, GI emphasizes the students' self-direction through group-centered decision making while the CI technique, according to Tan et al. (2006), focuses on the verbal presentation of academic subject matter proposed by the teacher to the students, whose primary role is listening and responding to the teacher's questions. This result rejected Jalilifar (2009) study which revealed that STAD is a more effective technique for improving EFL reading comprehension achievement whereas GI and CI did not develop reading comprehension significantly.

According to Jalilifar (2010), GI approach stifles student creativity and makes them too dependent on teacher lecturing; learning in this approach is a one-way process of the teacher asking questions and the students answering them. GI may not promote a positive effect on reading comprehension, and lack of significant effects on reading comprehension is not surprising, as studies mentioned earlier on CL hardly found significant differences in reading comprehension. The tasks constructed on the principles of GI did not promote the acquisition and practice of such reading comprehension strategies as summaries, headings, and identifying main ideas. Moreover, the students in the GI class were neither given tasks designed to develop reading strategies nor were they encouraged to do so in any way.

\section{References}

Brody, C., Baloche, L., Schmuck, R., Sherman, L., \& Sharan, Y., (2004). The Past and Future of Cooperative Learning. Paper presented at the Panel Session at IASCE Conference, Singapore.

Chastain, K. (1988). Developing Second-Language Skills. USA: Harcourt Brace Jovanovich, Inc. 
Chester, V. (2009). The Relationship between Cooperative Learning and Physics Achievement in Minority Students (Unpublished Doctoral Dissertation). Walden University, USA.

Ellis, R. (2003). Task-Based Language Learning and Teaching. New York: Oxford University Press.

Ghaith, G. M. (2002). The Relationship between Cooperative Learning, Perceptions of Social Support, and Academic Achievement. System.30, 263-273.

Griffee, D.T. (2012). An Introduction to Second Language Research Methods: Design and Data. Retrieved from http://www.teslej.org/pdf/ej60/sl_research_methods.pdf

Liang, T. (2002). Implementing Cooperative Learning in EFL Teaching: Process and Effects (Doctoral Dissertation). Retrieved from http://www.asian-efljournal.com/Thesis_Liang_Tsailing.pdf

Keshavarz ,S.M , Shahrokhi, M ., \&Talebi Nejad, M.R.(2014).The effect of cooperative leaning techniques on promoting writing skill of Iranian EFL learners. International Journal of language Learning and Applied Linguistics World, 5(1), 78-90.

Klimovienè, G., \& Statkevičienè, S. (2006). Using Cooperative Learning to Develop Language Competence and Social Skills. Studies About Languages, 8, 77-83.

Jacobs, G. (2004). Cooperative learning: Theory, Principles, and Techniques. Paper presented at the 1st International Online Conference on Second and Foreign Language Teaching and Research. Retrieved from http://www.readingmatrix.com/confrence/pp/proceedings/jacobs.pdf

Jalilifar, A. (2010). The Effect of Cooperative Learning Techniques on College Students' Reading Comprehension. System, 38, 96-108.

Johnson, D.W., \& Johnson, R.T., (2009a). An Educational Psychology Success Story: Social Interdependence and Cooperative Learning. Educational Researcher, 38, 365- 379.

Johnson, R.T., \& Johnson, D.W. (2009b). An Overview of Cooperative Learning. Retrieved from http://www.cooperation.org/pages/overviewpaper.html

Johnson, D.W., Johnson, R.T., \& Smith, K.A. (1998). Active Learning: Cooperation in the College Classroom. Edina, MN, USA: Interaction Book Company Publishing.

Johnson, D.W., Johnson, R.T., \& Holubec, E.J. (1998). Cooperation in the Classroom. Boston, MA, USA: Allyn and Bacon Publishing

Johnson, D.W., Johnson, R.T., \& Smith, K.A. (1998). Cooperative Learning Returns to College: What Evidence is there that it Works? Change, 1(2), 27-35.

Jones, K.A., \& Jones, J.L. (2008). Making Cooperative Learning Work in the College Classroom: An Application of the 'Five Pillars' of Cooperative Learning to Post- Secondary Instruction. The Journal of Effective Teaching, 8, 61-76.

Mackey, A., \& Gass, S.M. (2005). Second Language Research: Methodology and Design. Mahwah, New Jersey: Lawerence Erlbawn Associates, Inc.

Madden, N.A., Robert, J., \& Robert, E.S. (1986a). A Comprehensive Cooperative Learning Approach to Elementary Reading and Writing: Effects on Student Achievement, Center for Research on Elementary \& Middle Schools, Baltimore, Md.: The Johns Hopkins University.

Madden, N.A., Robert, J., \& Robert, E.S. (1986b). Reading Instruction in the Mainstream: A Cooperative Learning Approach. Center for Research on Elementary \& Middle Schools, Baltimore, Md.: The Johns Hopkins University, 1986b.

Myers, D., (2006). The National Evaluation of Reading Comprehension Intervention: Design Report. Mathematica Policy Research, Inc., Princeton, NJ.

Passi, A., \& Vahitvuori, S. (2001). From Cooperative Learning toward Communalism. Media Education Publication, 8 , 259-272.

Spada, N., \& Lightbown, P.M. (2002). Second Language Acquisition. In N. Schmitt (Ed.), An Introduction to Applied linguistics. Great Britain: Arnold.

Stevens, R.J., \& Robert, E.S. (1995). The Effects of a Cooperative Approach to Reading and Writing on Academically Handicapped and Nonhandicapped Students, The Elementary School Journal, 95 (3), 241-262.

Shaaban, K., \& Ghaith, G., (2005). The Theoretical Relevance and Efficacy of Using Cooperative Learning in the ESL/ EFL Classroom. TESL Reporter, 38, 14-28.

Tan, I.G.C., Sharan, S., \& Lee, C.K.E. (2006). Group Investigation and Student Learning: An Experiment in Singapore Schools. Marshal Cavendish Academic, Singapore.

Tracy, C., \& Barbara, H., (2003). Improving Reading Comprehension through Cooperative learning, (Unpublished MA Thesis). Sainte Xavier University.

Wilson, S.R. (1991). The Effects of Cooperative Learning on Reading Comprehension. Retrieved from http://www.proquest.umi.com

Zarei, A.A. (2012). The Effects of STAD and CIRC on L2 Reading Comprehension and Vocabulary Learning. Frontiers of Language and Teaching, 3(5), 161-173. 